\title{
Impact of Bioethics Education in Decision Making on Commercial Surrogacy: A Study with Medical Graduates
}

\author{
Manjeshwar Shrinath Baliga ${ }^{1}$, Princy Louis Palatty ${ }^{2}$, Paul Simon ${ }^{1}$, Prema D'Cunha ${ }^{2}$, \\ Bedakai Poornima Ramachandra Bhat ${ }^{1}$, Suresh Rao ${ }^{1}$, Pratima Rao ${ }^{1}$, \\ Devika Gunasheela ${ }^{3}$
}

${ }^{1}$ Bioethics Education \& Research Unit of the UNESCO Chair in Bioethics, at Mangalore Institute of Oncology, Pumpwell, Mangalore, Karnataka, India.

${ }^{2}$ UNESCO Bioethics South India Unit at Father Muller Medical College, Kankanady, Mangalore, Karnataka, India.

${ }^{3}$ Gunasheela Surgical and Maternity Hospital, Dewan Madhava Road, Basavanagudi, Bengaluru, Karnataka.

Corresponding Author: Manjeshwar Shrinath Baliga.

E-mail: msbaliga@gmail.com

\begin{abstract}
Knowledge, attitudes and practices of medical ethics among 297 undergraduate medical interns of four medical colleges from eastern part of India were assessed using a self administered structured questionnaire. Questions on source of medical ethics, codes and guidelines were set to assess the knowledge of medical ethics while importance of ethics, autonomy, justice and confidentiality were used as questions to assess attitudes towards medical ethics. Practices of medical ethics, however, were assessed by questions on frequency of ethical dilemma, research ethics etc. Out of 297, 259 interns $(87.2 \%)$ responded. 106 interns $(40.9 \%)$ said that sources of knowing medical ethics are lectures and/or seminars. Others told either through own reading $(20.6 \%)$, training $(19.8 \%)$ or during doing work $(18.7 \%)$. In code \& guidelines, all interns knew Hippocratic Oath but 52.3\% interns were aware of Indian Council of Medical Research's code of ethics. $87.6 \%$ interns admitted importance of ethics in their work but $22.5 \%$ interns believed that consent is required only during operation and not at the time of taking blood. In practice of ethics $52.5 \%$ interns told that ethical dilemma comes once in a month. $12.4 \%$ interns, however, told that they faced ethical dilemma in their daily work. Regarding application of consent form in human research, $58.1 \%$ interns knew about informed consent. $100 \%$ interns had no clear cut idea about ethical issue on end-of-life. Implementation of teaching on medical ethics seems to be important in undergraduate medical curriculum in this study zone.
\end{abstract}

Key words: attitudes, knowledge, medical ethics, practice, undergraduate medical interns

\section{INTRODUCTION}

Medical ethics, the term dates back to 1803 , is a combination of moral principles and values that are applied to take judgement in the practice of medicine. The first code of medical ethics was published as early as $5^{\text {th }}$ century during the reign of Ostrogothic king Theodoric the great. Western people preached medical ethics through Hippocratic Oath and Christian teachings. Traditional medical ethics guidelines were developed by Muslim, Catholic and Jewish thinkers. In $18^{\text {th }}$ century English physician Thomas Percival wrote a book on medical ethics which is considered as gateway of ethics in modern medicine. Based on this book, the American Medical 
Association developed code of ethics in medical practice. All countries have now their own code of ethics in medical practice [1].

There are six principles/pillars of medical ethics. These are autonomy (respect for the patient's right to self-determination), beneficence (the duty to 'do good'), non-maleficence (the duty to 'not do bad'), justice (to treat all people equally and equitably), dignity (the patient and the person treating the patient have the right to dignity), truthfulness and honesty (patients deserve to know Truth about their illness and treatment). These principles are highlighted in the guidelines of medical ethics of different countries [2-7].

Until the early 1980s it was thought that ethics education in medical curriculum is simply wastage of time as doctors could come to knowmedical ethics adequately in course of patient care [8]. In 2010 in one technical bulletin of World Health Organization, however, it was commented ...... learning of professionalism and medical ethics is like acquiring "heart". Therefore, medical ethics is at the "heart" of medical practices and this fact needs to be stressed repeatedly to medical students [9]. It was, thus, felt that medical ethics is one of the most important components of medical education and in addition to learn different subjects in medical curriculum, medical students must know medical ethics [10]. Learning medical ethics will not only solve many problems that they may face in future in their daily practice but also make them virtuous doctors [11-12].

It was, therefore, thought worthwhile to assess knowledge, attitudes and practices of medical ethics among undergraduate medical interns of few medical colleges from eastern part of India.

\section{METHODOLOGY}

A cross sectional study was undertaken to assess knowledge, attitudes and practices of medical ethics among 297 undergraduate medical interns of four medical collegesfrom eastern part of India using a self - administered structured questionnaire. Name of the medical colleges and number of participating interns were as follows -

1. Kishanganj Medical College, Kishanganj, Bihar - 74 medical interns

2. Katihar Medical College, Katihar, Bihar - 82 medical interns.

3. R. G. Kar Medical College, Kolkata, West Bengal - 69 medical interns

4. North Bengal Medical College, Siliguri, North Bengal - 72 medical interns

Questions on source of medical ethics, codes and guidelines were set to assess the knowledge of medical ethics. A semi-structured questionnaire was prepared which was validated and then distributed among the students. The results were tabulated and presented using descriptive statistics. The questionnaire is presented in Appendix 1.

\section{RESULTS}

Out of the 297 interns that were administered the questionnaire, $259(87.2 \%)$ responded to the complete questionnaire. Incomplete and illegible questionnaires were discarded.

On assessing the knowledge amongst medical interns, $105(40.9 \%)$ said that they derived bioethics knowledge from lectures, 53 (20.6\%) derived it from own reading, 51 (19.8\%) from training and $49(18.7 \%)$ from work. It was heartening that all students $(100 \%)$ knew the contents of the Hippocratic oath. Only 135 (52.3\%) students knew the details of the Indian Council of Medical Research (ICMR) code of ethics.

On assessing the attitudes of students towards medical ethics, 227 (87.6\%) felt that medical ethics was very important and had great relevance in their day to day work. $58(22.5 \%)$ felt that consent was need only for surgeries and not for blood collection while the rest felt that consent was needed for all procedures. $212(81.8 \%)$ students mentioned that it not needed that patients be informed of all wrong doing while the rest thought otherwise. 57 (21.9\%) felt that it was alright to charge some patients more in order to provide funds for the management of poor patients while the rest thought that all patients must be charged equally. 107 (41.5\%) felt that maintaining confidentiality in the modern era was difficult and must be done away with. 
On studying the practice of medical ethics amongst medical interns it was noted that 91(35.1\%) occasionally encountered ethical dilemmas in clinical work while $136(52.5 \%)$ encountered these dilemmas at least once a month. 135 (51.9\%) said that it was a must to take informed consent during research on human subjects while the rest were sadly not aware of the same. All the students had no clear ideas on the ethical issues at the end of life which is a very important aspect of medical practice.

\section{DISCUSSION}

Acharya and Shakya [13] studied knowledge, attitude and practices of medical ethics among medical interns in a medical college in Kathmandu. They noted that most common source of medical ethics was lectures/seminars (35.7\%) followed by experience at work (24.5\%), training $(21.4 \%)$ and own reading $(17.3 \%)$. Almost similar findings were observed in a study among residents and interns in Pakistan [14]. In another study it was reported [15] that common source of medical ethics is lecture (54.7\%). However, in the present study we have noted that the source of knowledge of medical ethics is primarily lectures or seminars (40.9\%).

Idea on ethical codes and guidelines is the basis of knowledge of medical ethics. In this study it has been observed that only 52.3\% interns were aware of Indian Council of Medical Research's code of ethics. In other studies, however, it has been noted that $60.9 \%$ medical interns and $50 \%$ surgical residents and interns know the code of ethics published by the Medical Councils of their countries [13-14].

In 2006 Hariharan and others [16] showed that $90 \%$ of the nursing staff was of the opinion that knowledge of ethics is important for their daily work. In another study it was demonstrated that $91.3 \%$ of medical intern students realized importance of medical ethics [13]. In the present study we, however, found that $87.6 \%$ interns admitted importance of ethics in their work. In the present study $22.5 \%$ interns stated that consent is required only during operation and not at the time of taking blood when other studies $[13,17]$ showed that only $21.7 \%$ of medical interns and $9 \%$ of medical students supported the statement. Further, $18.2 \%$ interns were of the opinion that patients should always be informed of wrong doing. $21.9 \%$ interns supported that doctors may charge more money from the financially sound patients in order to raise fund to treat poor patients. $41.5 \%$ interns were of the opinion that confidentiality can't be kept in modern era and should be abandoned. All these indicate poor attitude of the medical intern students under study towards medical ethics.

In practice of ethics $52.5 \%$ interns told that ethical dilemma comes once in a month while in other studies it was shown that $43.5 \%$ interns told that ethical dilemma comes once in a month [13]. Regarding application of consent form in human research, only 58.1\% interns under present study knew about informed consent but as per other study [13]. 82.6\% of interns were involved in taking informed consent. Further, $100 \%$ interns of this study had no clear cut idea about ethical issue on end-of-life.

Experts are of the opinion that ethics teaching influences the attitude of medical professional [18] and this teaching should be started right from under graduate training [19-20]. Several countries have called for a basic curriculum in ethics for students in the medical profession as a result ethics courses are now common in medical schools of many countries [21-22]. Results of the present study also advocate immediate implementation of medical ethics teaching in medical colleges of this study zone.

\section{CONCLUSIONS}

To know the level of knowledge, attitude and practices of medical ethics among few medical interns of eastern part of India we had undertaken a base line study and the results of the study showed that medical interns under study have limited knowledge, attitudes and practices of medical ethics. Implementation of teaching on medical ethics is, therefore, important in undergraduate medical curriculum in this study zone. 


\section{REFERENCES}

1. Ramana KV, Kandi S, Boinpally PR. Ethics in medical education, practice and research : An Insight. Africa Health Research Organisation 2013;6(6):599-602.

2. Ashley P, Benedict M., Jean deBlois, and Kevin D. O'Rourke. Health Care Ethics: A Catholic Theological Analysis,5th Edition. Washington, DC: Georgetown University Press, 2006.

3. BeauchampTom, James Childress. Principles of Biomedical Ethics, 4th Edition. New York: Oxford University Press, 1994.

4. Carrick, Paul. Medical Ethics in the Ancient World. Washington, DC: Georgetown University Press, 2001.

5. Jonsen, Albert R, Stephen Toulmin. The Abuse of Casuistry: A History of Moral Reasoning, Berkeley, CA: University of California Press, 1988.

6. Pence D, Gregory E.Classic Cases in Medical Ethics, 3rd Edition. New York: McGraw-Hill Higher Education, 2000.

7. Mappes C, Thomas A., David DeGrazia (eds.). Biomedical Ethics, 6th Edition. New York: McGraw-Hill Higher Education, 2006.

8. Bickel J. Integrating Human Values Teaching Programs Into Medical Students Clinical Education, American Association of Medical Colleges, Washington DC, 1986.

9. WHO technical report on Facilitators Guide for teaching medical eethics to undergraduate students in medical colleges in the South -East Asia Region, 2010.

10. Mattick K, Bligh J. Undergraduate ethics teaching : revising the consensus statement. Med. Educ 2006;40(4):329-32.

11. Ravindran GD. Medical ethics education in India. Indian J Med Ethics 2008;5(1):18-19.

12. Gordon MS. Teaching and learning medical ethics and law in UK medical schools. Clin. Ethics 2007;5(3):156-8.

13. Aacharya RP, ShakyaYL. Knowledge, attitude and practices of medical ethics among medical intern students in a medical college in Kathmandu. Bangladesh J Bioethics 2015; 6(3):1-9.

14. Shirazi B, Shamim MS, Ahmed A. Medical ethics in surgical wards: Knowledge, attitude and practices of surgical team members in Karachi. Indian J Med Ethics 2005;2(3):94-6.

15. Chatterjee B, Sarkar J. Awareness of medical ethics among undergraduates in a West Bengal Medical College. Indian J Med Ethics 2012;9(2):93-100.

16. Hariharan S, Jonnalagadd R, Walrond E, Moseley H. Knowledge, attitude and practice of healthcare ethics and law among doctors and nurses in Barbados. BMC Med Ethics 2006; 9(7):715.

17. Walrond ER, Jonnalagadda R,Hariharran S,Mooseley HS. Knowledge, attitude and practice of medical students at the Cave Hill campus in relation to ethics and law in health care. West Indian Med J 2006;55(1):42-7.

18. Elger BS, Harding TW. Terminally ill ppatients and Jehovah"switness : teaching acceptance of patients refusals to vital treatment. Med Educ 2002;36:479-88.

19. 19.Sulmasy DP, Geller G, Levine DM,Faden RR. A randomized trial of ethics education for medical house officers. J Med Ethics 1993;19:157-63.

20. McKneally MF, Singer PA. Bioethics for clinicians : Teaching bioethics in clinical setting. CMAJ 2001;164(8):1163-7.

21. Lakhan SE, Hamlat E, McNamee T, Laird C. Time for a unified approach to medical ethics [editorial]. Philos Ethics Humanit Med 2009;4:13.

22. Stirrat GM, Johnston C, Gillon R, Boyd K. Medical ethics and law for doctors of tomorrow: the 1998 consensus statement updated. J Med Ethics 2010;36:55-60.

Acknowledgements - Nil

Source of Funding - Nil

Conflict of Interest $-\mathrm{Nil}$ 


\section{Appendix 1 - Questionnaire used in the study}

1. Do you consider importance of ethics in your work?
a) Yes
b) No

2. Do you consider that consent is required only in case of operation \& not at the time of blood taking?
a) Yes
b) No

3. Do you think that patients should always be informed of wrong doing?
a) Yes
b) No

4. Is it ethical that certain doctors charge more money from the patients in order to raise fund to treat poor patients?
a) Yes
b) No

5. Do you think that confidentiality can't be kept in modern era and should be abandoned?
a) Yes
b) No

Practices of medical ethics, however, were assessed by questions on frequency of ethical dilemma, research ethics etc.

Questions were -

1. Frequency of ethical dilemma -
a) Occasional
b) Once in a month
b) Daily work?

2. Do you consider informed consent should have to be taken when researching on human a) Yes b) No

3. Have you got clear cut idea about ethical issue on end-of-life?

a) Yes b) No 